\title{
Clinical and Experimental Aspects of Injection Injuries of Peripheral Nerves
}

\author{
FRED GENTILI, ALAN R. HUDSON, DANIEL HUNTER
}

SUMMARY: Injury to peripheral nerves complicating deep intramuscular injections of antibiotic and other agents is well recognized and can result in significant permanent neurological deficit. The purpose of this paper is to review the subject of nerve injection injuries, and report on a series of recent experimental studies carried out in this laboratory designed to improve our understanding of the pathophysiology of this condition and help provide a rational basis for its treatment. A wide variety of chemotherapeutic, prophylactic, and local anaesthetic agents in common use were injected into the sciatic nerve of the adult Wistar rat. Both intrafascicular and extrafascicular injections were examined. Results revealed that

RESUME: Les lésions aux nerfs périphériques consécutives aux injections intramusculaires profondes d'antibiotiques ou autres agents sont bien reconnues et peuvent causer des déficits neurologiques permanents. Dans le présent article nous ferons la revue des connaissances à ce sujet et rapporterons les résultats d'expériences chez l'animal concues pour élucider la pathophysiologie de cette condition et en améliorer le traitement. Après injection d'une multitude d'agents, par voie intra ou extra fasciculaire, dans le nerf sciatique du rat Wistar, il devint évident que le site de l'injection est le facteur majeur déterminant the site of injection was the most crucial factor in determining the degree of nerve fiber injury. Following intrafascicular injection, the degree of injury varied significantly, depending upon the specific agent injected. The most severe injuries were associated with wide-spread axonal and myelin degeneration. Pathological alterations in the nerve were evident as early as 30 minutes following injection injury. Regeneration was a constant finding in nerve damage by injection of the various agents. The mechanism of injury appeared to be a direct toxic effect of the injected compound on neural tissue, with an associated break down of the bloodnerve barrier.

l'amplitude de l'atteinte de la fibre nerveuse. Après les injections intrafasciculaires le degré de la blessure variait énormément selon lagent spécifique injecté. Les lésions les plus sévères étaient associées à une dégénérescence diffuse axonale et myélinique. Les altérations pathologiques dans le nerf étaient évidentes dès 30 minutes après l'injection. Une régénérescence était constamment constatée à la suite de ces injections. Le mécanisme de la blessure semble être un effet toxique direct du composé injecté sur le tissu neural, avec une atteinte associée de la barrière sangnerf.

\section{INTRODUCTION:}

Injury to peripheral nerves complicating deep intramuscular injections of antibiotic and other agents is well recognized. These nerve injuries are of particular concern for they may not only result in significant permanent disability for the patient, but also provide the basis for litigation. A lack of understanding of the pathological mechanisms involved has also contributed to considerable controversy surrounding the treatment of postinjection nerve injuries. The purpose of this paper is to review the subject of nerve injection injuries and report on a series of recent experimental studies carried out in our laboratory, designed to improve our understanding of the pathophysiology of this condition and help provide a rational basis for its treatment (Gentili et al, 1979 a, b, c,; Hudson et al, 1979).

\section{Clinical Reports}

Peripheral nerve injection injuries have been recognized for over half a century (Turner, 1920). Kolb and Gray (1946) reported a "localized peripheral neuritis" occurring one to three weeks following multiple intramuscular injections of penicillin preparations. Broadbent et al (1949), described the clinical features of penicillin-induced peripheral nerve lesions characterized by severe pain at the onset of injection radiating along the course of the affected nerve and followed rapidly by motor and sensory impairment of the nerve. Several authors (Curtis and Tucker, 1960; Combes et al, 1960; Gilles and French, 1961) stressed the increased frequency of sciatic nerve injection injuries in premature infants and paediatric patients following intragluteal injections.

Whereas some authors have reported a favourable outcome following this 
type of injury (Kolb and Gray, 1946; Curtis and Tucker, 1960), others have found recovery of neurological function to be disappointing (Combes et al, 1960; Gilles and French, 1961). Clark et al (1970), (1972) in reviewing the literature and their own extensive clinical experience with nerve injection injuries noted that neurological deficit was of rapid onset and often quite profound with a more severe impairment of motor than sensory function. Followup studies revealed the majority of patients to have some residual motor deficit, only $14 \%$ showing complete recovery.

Because of its size and the frequency of intramuscular injections in the buttock, the sciatic is by far the most commonly affected nerve. However, injection injury of other peripheral nerves has been reported, including the radial (Ling and Loong, 1976) ulnar (Broadbent et al, 1949), median (Hudson et al, 1979), axillary and lateral femoral cutaneous nerve (Clark et al, 1970).

To date, a wide variety of therapeutic and other agents have been implicated in injection accidents, including antibiotics, analgesics, vaccines, vitamin preparations and local anaesthetic agents (Curtis and Tucker, 1960; Combes et al, 1960; Gilles and French, 1961; Moore, 1955).

A number of pathological mechanisms have been postulated to account for the resulting nerve damage, including an allergic peripheral neuritis (Kolb and Gray, 1946), direct needle trauma (Scheinberg and Allensworth, 1957), secondary construction by external scar (Combes et al, 1960), ischemic injury (Con Hochstetter, 1955), and direct neurotoxic properties of the injected agent on neural tissue (Gilles and French, 1961; Clark et al, 1970).

\section{Experimental Studies}

Woodall et al (1950) noted that most of the pathological changes following injection of the sciatic nerve of experimental animals with penicillin preparations were intrafascicular suggesting that extraneural compression was not a mechanism of injury. Tarlov et al (1951) on the basis of light microscopic observations reported axonal and myelin degeneration with connective tissue scarring following injection of various antibiotic agents into rat sciatic nerve. They concluded that damage to neural structures was primarily due to the introduction of material directly into the parenchyma of the nerve and was not seen when injection was into the epineural tissues. Holbrook and Pilcher (1950) reported granuloma formation following the injection of various penicillin compounds into the sciatic nerve of the dog. These authors also noted that certain preparations of the same agent were much more damaging to the nerve than others. Hanson (1963) found that the degree of injury was dependent to some extent on the vehicle of suspension. Combes and Clark (1960) and Clark et al (1970) have investigated injection injuries of the sciatic nerve in several animal species, using both pathological and neurophysiological parameters. These authors reported that the two most important factors determining the degree of nerve injury were the nature of the injected material and the site of injection within the nerve.

More recently, electron microscopic studies have revealed wallerian degeneration with the subsequent regeneration of nerve fibers following injection of phenol and alcohol into the sciatic nerve of the rat (Burkel and McPhee, 1970; Sun and White, 1974). Despite these experimental studies questions remain about individual drug and dose factors, and little is known about the precise time course of this type of nerve injury (Clark et al, 1970).

\section{METHODOLOGY}

The sciatic nerve of adult Wistar rats was chosen for study. To date over 500 nerve injections have been carried out in over 300 animals. The nerve was carefully exposed with the aid of the operating microscope and injected using finger pressure and a tuberculin spring with a 30 gauge needle at a standard location just distal to its exit from under piriformis. Injection was made either directly into the nerve fascicle (intrafascicular) or into the surrounding epineurial tissues (extrafascicular) (Fig. 1). In an attempt to clarify the relationship between specific

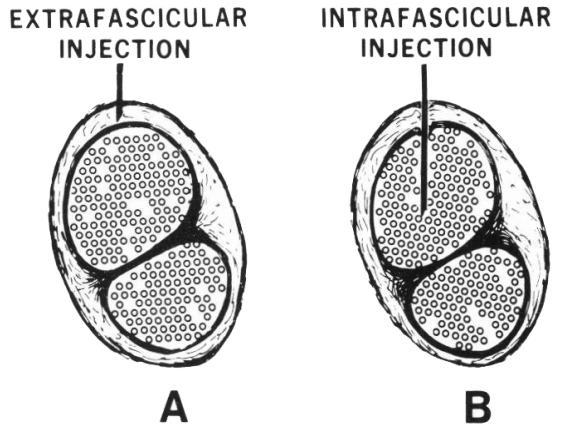

Figure l-Schematic illustrations demonstrating (A) intrafascicular and (B) extrafascicular sites of drug injection.

compounds and the degree of nerve injury, a wide variety of chemotherapeutic, prophylactic and local anaesthetic agents in common use were tested. Evaluation of the resulting changes in the injected nerve was based on both light and electron microscopic observations. Examination of tissue at different times following injection allowed documentation of the degree of both degeneration and regeneration, and delineation of the precise time course of this type of nerve injury. The relationship of drug dosage, site of injection and the degree of injury and subsequent recovery was also examined.

Alterations in the endoneurial microcirculation and blood nerve barrier following injection injury was investigated with a fluorescent protein tracer technique using Evans blue albumin (Steinwall and Klatzo, 1966) and by electron microscopic tracing of horseradish peroxidase as previously described by Graham and Karnovsky (1966).

\section{Nerve Injection with Antibiotic and other Chemotherapeutic Agents}

In an initial series of experiments the injection of a variety of agents commonly administered by intramuscular injection was studied (Gentili 1979a). Antibiotic compounds included gentamicin sulfate (Schering Corp. Ltd.), cephalothin sodium (Eli Lilly \& Co. (Canada) Ltd.), benzylpenicillin (Ayerst Co.) and chloramphenicol sodium (Parke Davis \& Co.). The injection of diazepam (Roche Laboratories), meperidine hydrochloride (Winthrop Laboratories), chlorpromazine hydrochloride (Poulenc, Ltd.), Gravol (Horner Company), chlordiaze- 
poxide (Roche), and imferon (Fisons, Ltd.) was also investigated. Physiological saline (.9\% sodium chloride) was used as a control agent throughout.

The degree of sciatic nerve injury seen following injection of the agents listed varied significantly ranging from minimal or no damage to severe widespread axonal and myelin degeneration. The exact site of drug injection was the single most crucial factor in determining the extent of nerve fiber injury. (Table 1). Injection of these compounds around the nerve or in the epineurial tissues (extrafascicular injection) did not result in any significant nerve fiber damage in the majority of cases (Fig. 2). By contrast, with the exception of normal saline injected control nerves, some degree of nerve fiber injury was consistently seen following the intrafascicular injection of the same agents.

The most severe degree of nerve fiber damage followed the intrafascicular injection of benzylpenicillin and diazepam. At three and one half weeks following injection widespread axonal and myelin degeneration was evident throughout the injected fascicle (Fig. 3). A moderate degree of nerve fiber injury was seen after the intrafascicular injection of chloramphenicol, gentamicin, imferon and cephalothin with complete loss of large myelinated fibers and relative sparing of smaller, thinly myelinated fibers.

Extrafascicular injection was, however, not always innocuous, and in the case of several agents including benzylpenicillin, diazepam and chlorpromazine, extrafascicular injection also produced a degree of nerve fiber damage.

The mechanism of injury following extrafascicular injection was not the result of external compression by scar, but was related as with intrafascicular injections to intraneural pathology.

Our findings therefore, appear to confirm the previous clinical impression that some compounds possess greater potential for neural damage than others. Since most injectable preparations are mixtures of the pharmacologically active compound, their solvents and buffering agents, possible neurotoxic properties of the latter must also be considered. Indeed, the

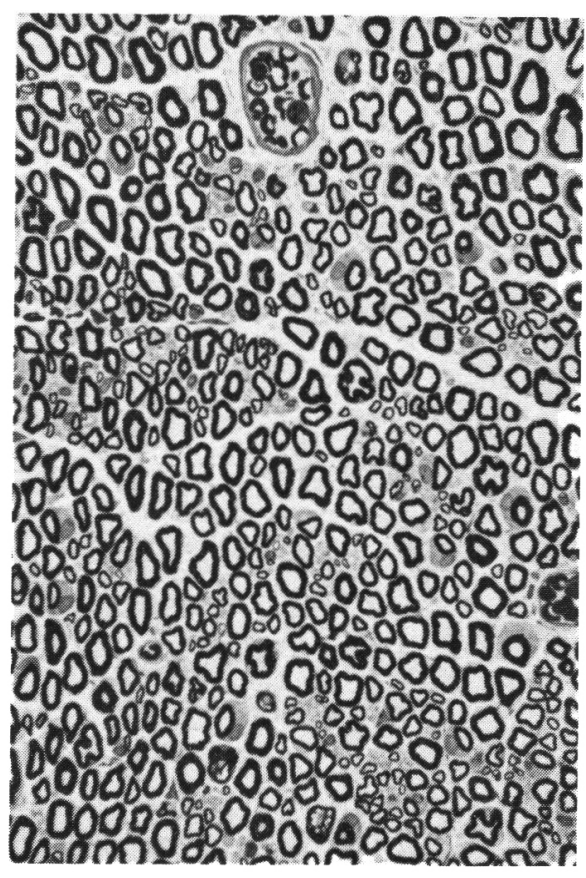

Figure 2 - Transverse section of rat sciatic nerve 3 weeks after extrafascicular injection of cephalothin (Keflin). Note the normal appearance and distribution of the myelinated fiber population with no evidence of nerve fiber injury. (Toluidine blue stain, $X 760$ )

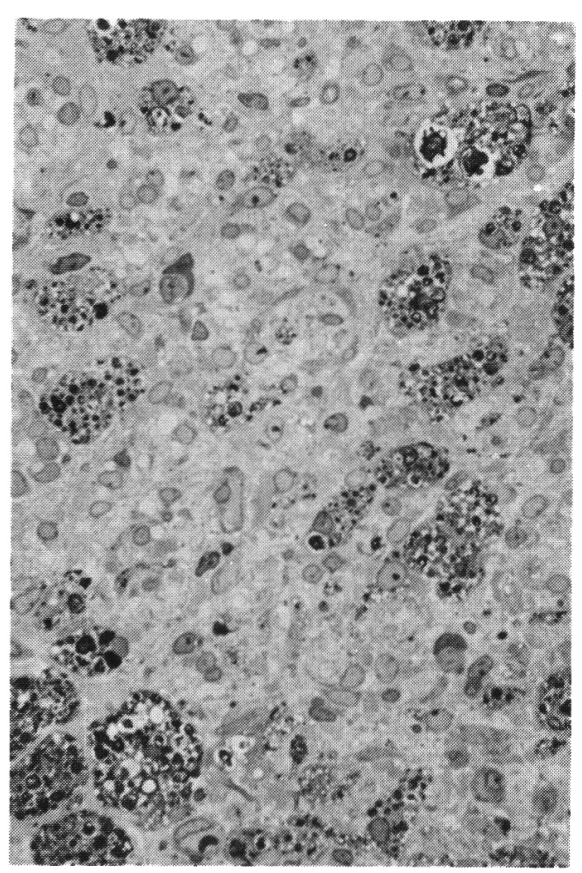

Figure 3 - Rat sciatic nerve 3 weeks following intrafascicular injection of benzylpenicillin showing severe, diffuse nerve fiber damage with evidence of active degeneration. No normal axons are seen. (Toluidine blue stain, $X 760$ )
TABLE I

Nerve Injury Following Injection of Antibiotic and Other Chemotherapeutic Agents

\begin{tabular}{lcc}
\hline AGENT & $\begin{array}{c}\text { DEGREE OF NERVE FIBER INJURY } \\
\text { Extrafascicular } \\
\text { Injection }\end{array}$ & $\begin{array}{c}\text { Intrafascicular } \\
\text { Injection }\end{array}$ \\
\hline Gentamycin (Schering) & - & ++ \\
Cephalophin (Eli Lilly) & - & ++ \\
Benzylpenicillin (Ayerst) & + & +++ \\
Chloramphenicol (Parke Davis) & - & ++ \\
Diazepam (Roche) & + & +++ \\
Chlordiazepoxide (Roche) & + & +++ \\
Chlorpromazine (Poulenc) & + & +++ \\
Meperidine (Winthrop) & - & +++ \\
Dimenhydrinate (Gravol, Horner) & + & ++ \\
lron-dextran (Fisons) & - & + \\
Blood & - & - \\
Sodium Chloride (0.9\%) & - & + \\
\hline
\end{tabular}

\footnotetext{
- no eviōence of nerve fiber injury

$+\quad$ Minimal nerve fiber injury

+ Moderate nerve fiber injury

+++ Severe nerve fiber injury
} 
severe degree of damage found following the intrafascicular injection of diazepam (Valium, Roche Laboratories) may, in part, be attributed to one of it's buffers being $40 \%$ propylene glycol, a compound previously shown to produce diffusely necrotizing changes when injected into the sciatic nerve of the cat and rat (Combes and Clark, 1960; Chino et al, 1974). The degree of nerve injury was also related, to some degree, to the quantity of drug injected. Whereas 10,000 units of benzylpenicillin and $0.1 \mathrm{mgs}$ of diazepam produced a moderate degree of injury to predominately large, heavily myelinated axons and relative sparing of the smaller, thinly myelinated fibers, injection of 500,000 units of benzylpenicillin and $2.5 \mathrm{mgs}$ of diazepam produced almost total axonal and myelin degeneration. That it was not related to the volume of fluid injected was shown by injecting equal volumes of normal saline with no significant damage to the nerve.

The correlation between fiber size and succeptability to injection injury is of interest and a number of agents produced degeneration of large myelinated fibers with relative sparing of smaller, thinly myelinated nerve fibers. These results are in keeping with the neurophysiological studies of Clark et al (1970) who noted that conduction in large motor fibers was affected earlier and more severely than in smaller sensory fibers after injection injury in cats, and support the clinical observation that motor function is often more significantly disturbed than sensory function.

Although some thickening of the perineurium was a constant feature following intrafascicular injection, there was surprisingly little evidence of extensive intrafascicular fibrosis. This is in contrast to reported clinical experience in which extensive intraneurial fibrosis is often encountered at operation. We initially postulated that the difference between our experimental results and clinical experience may have been related to an associated vascular injury and to the effects of an admixture of drug and blood elements on the human nerve. Indeed, subsequent studies have revealed that injection of various agents together with blood (Gentili et al, 1979 B) did result in a greater degree of intraneurial fibrosis with the presence of a significantly greater number of fibroblasts in the endoneurium than was seen following the injection of the compounds alone (Fig. 4).

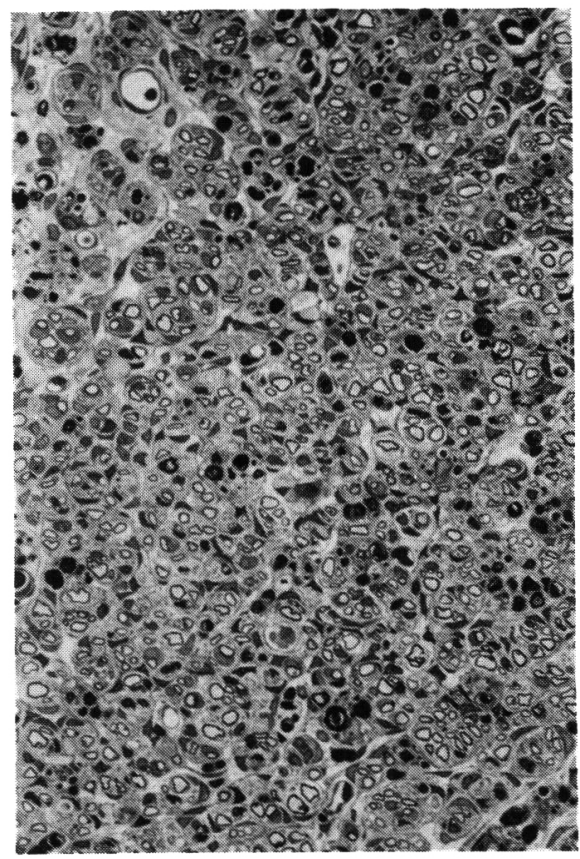

Figure 4 - Sciatic nerve 4 weeks after intrafascicular injection of an admixture of diazepam (Valium) and blood. The marked cellular reaction seen among the regenerating fibers suggests a significant degree of intrafascicular fibrosis. (Toluidine blue stain, $X 760$ )

\section{Nerve Injection with Local Anaesthetic Agents}

As agents designed to be injected into or near peripheral nerves, local anaesthetic compounds are commonly thought to possess no neurotoxic properties. Nevertheless, a wide spectrum of neurological deficits, ranging from mild sensory paresthesia to severe motor paralysis, have been reported following regional anaesthesia (Bonica, 1949; Moore, 1955; Selander et al, 1977). Recently, we reported on the effect of both intrafascicular and extrafascicular injection of a variety of local anaesthetic agents on rat sciatic nerve (Gentili et al, 1979 C). This included various preparations of lidocaine hydrochloride with and without epinephrine (Xylocaine, Astra
Chemicals Limited); bupivacaine hydrochloride (Marcaine, Winthrop Laboratories); mepivacaine hydrochloride (Carbocaine, Winthrop Laboratories); procaine hydrochloride (Novacaine, Winthrop Laboratories); and tetracaine hydrochloride (Pontocaine, Winthrop Laboratories).

Without exception, extrafascicular injection of the various compounds tested did not result in any significant nerve injury as assessed by both light and electronmicroscopy. By contrast, pathological changes which varied from occasional nerve fiber injury at the site of injection to severe axonal and myelin degeneration of the entire fascicle were observed following intrafascicular injection of these same agents.

Marcaine and Carbocaine appeared

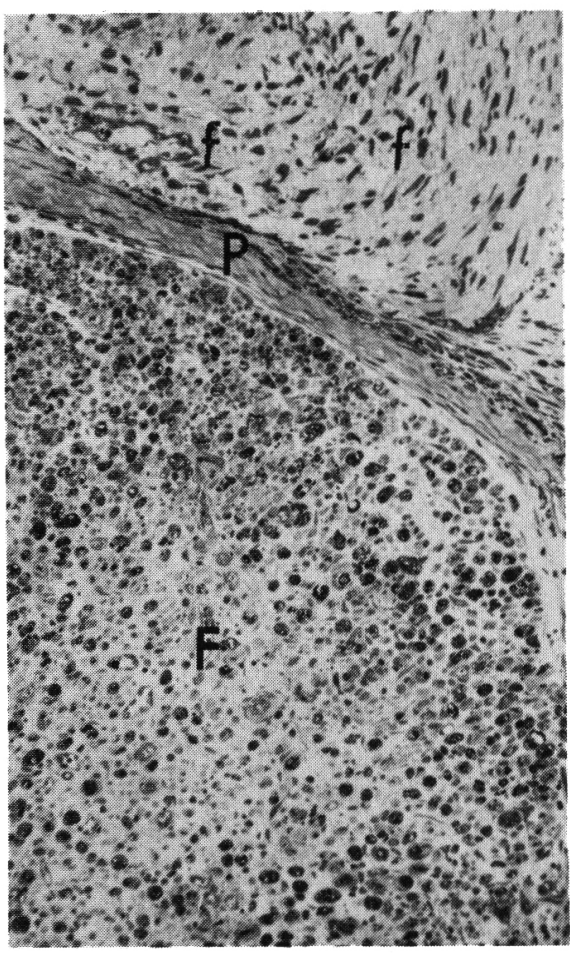

Figure 5 - Light photomicrograph showing part of a sciatic nerve fascicle 11 days after intrafascicular injection of tetracaine (Pontocaine) 1\%. A severe degree of nerve injury with total disruption of the internal architecture of the fascicle and active degeneration is evident. Note also, moderate thickening of the perineurium and surrounding fibrosis. F, fascicle; $f$, fibrosis; $P$, thickened perineurium. (Toluidine blue stain, X 760) 
to have the least toxic effect on neural tissue with only the occasional damaged nerve fiber evident at the injection site. The lidocaine group of anaesthetic agents resulted in a moderate degree of nerve injury. Damage was often focal, involving only part of the fascicle in which areas of axonal degeneration and gragmentation of myelin sheaths could be seen. Although small changes in concentration ( 1 vs. $2 \%$ ) and the presence or absence of epinephrine in the solution, did not significantly alter the results, the carbonated form of lidocaine (lidocaine hydrocarbonate) did result in a more severe axonal degeneration. The most severe damage was seen following the injection of procaine $2 \%$ and tetracaine $1 \%$ (Fig. 5). At one week, these agents resulted in widespread damage throughout the fascicle with degeneration of axons and myelin sheaths.

Differences in the duration of action, $\mathrm{pH}$ or osmolality of the injection solutions did not appear to account for the wide range in neurotoxicity noted between the various classes of agents. It was concluded that the neural damage following intrafascicular injection of local anaesthetics was related to a direct toxic effect of the anaesthetic agent. Based on these findings, it was recommended

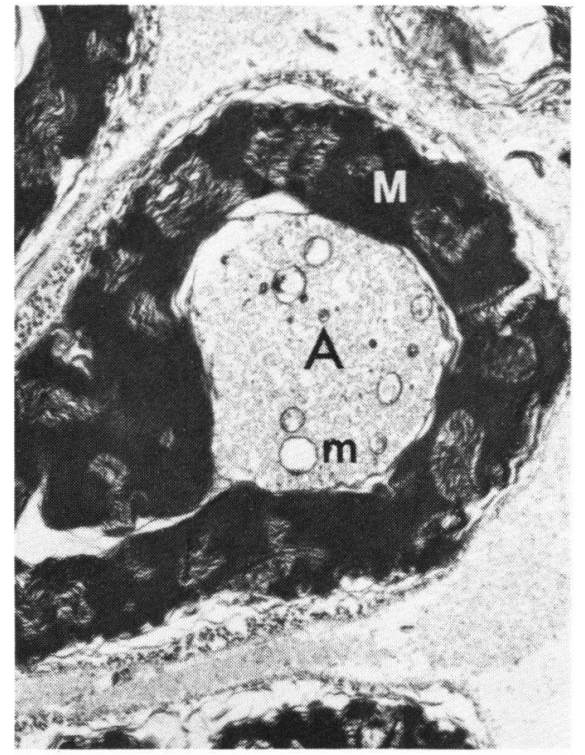

Figure 6 - Electronmicrograph of rat sciatic nerve 3 hours after intrafascicular injection of chlordiazepoxide (Librium). There is evidence of damage to the nerve fiber with splitting of myelin lamellae and swelling of mitochrondria within the axoplasm. A, axon; $m$, swelling of mitochondria; $M$, myelin sheath. (Lead citrate stain, $X$ 7280)

that intraneural injection of local anaesthetic agents be avoided and that if pain and paresthesia are noted at the beginning of an injection, intrafascicu- lar injection should be suspected and the position of the needle altered.

\section{Time Course Relationship Following Nerve Injection Injury}

The time course of nerve injection injury was studied in a series of animals in which nerves were examined at various times following intrafascicular injection. During injection the solution spread extensively both proximally and distally along the injected fascicle. The nerve often appeared pale with small, petechial hemorrhages on the surface of the fascicle. With agents causing significant nerve damage, changes were evident microscopically quite soon after injection. At 30 minutes, the nerve showed wide separation of axons which were often crowded towards the periphery of the fascicle. Ultrastructual studies revealed the earliest changes to be abnormalities of myelin with focal splitting of myelin lamellae (Fig. 6). By 6 hours there was further fragmentation of myelin and axonal alterations characterized by swelling of mitochondria within the axoplasm. Although most marked at the site of injection, these changes were seen for up to $1 \mathrm{~cm}$. proximally and distally. At 24 hours

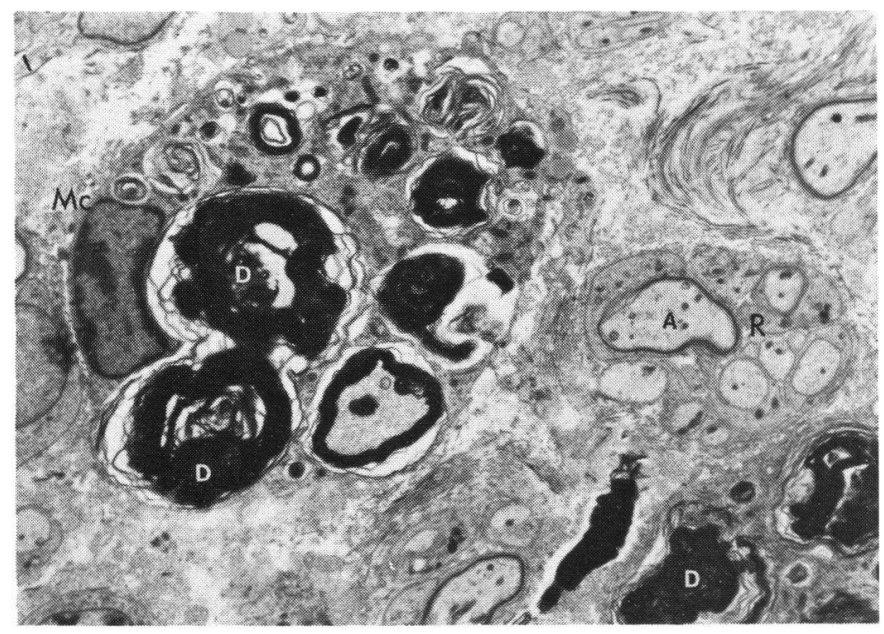

Figure 7 - Electronmicrograph of sciatic nerve 11 days after intrafascicular injection of procaine $2 \%$ (Novocaine), showing active degeneration with macrophages actively digesting myelin. There is also evidence of early regeneration with axonal sprouts, some of which have acquired thin layers of myelin. A, axon; $M$, myelin; Mc, macrophage; $D$, degenerating fiber; $R$, regenerating unit. (Lead citrate stain, $X$ 6589)

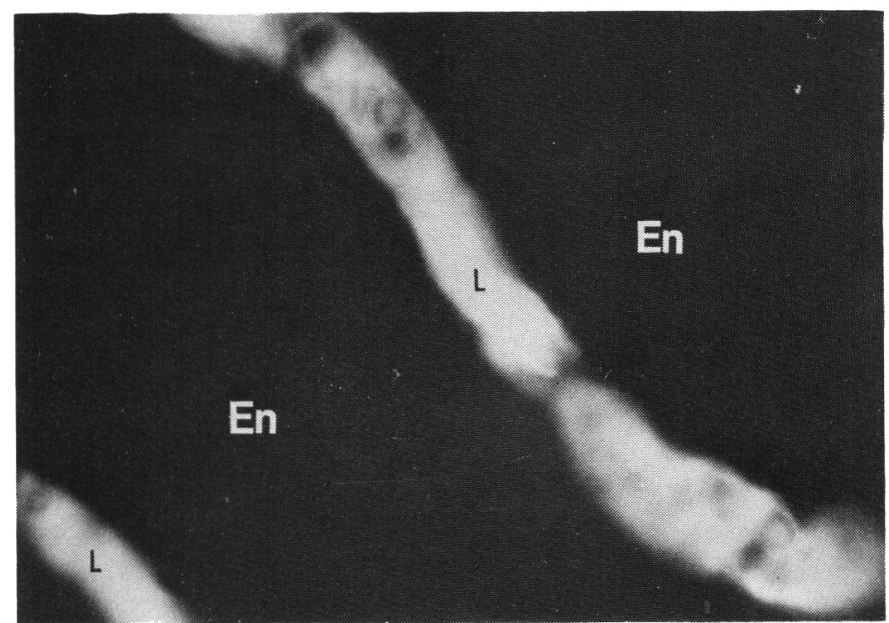

Figure 8 - Fluorescent micrograph of a longitudinal section of normal rat sciatic nerve $\mathbf{4 5}$ minutes after intravenous injection of Evans blue albumin (EBA) showing an endoneurial microvessel. The EBA protein tracer is seen to be confined to the lumen of the vessel, none appearing in the extravascular endoneurial space. En, endoneurium; L, lumen of endoneurial microvessel. (X 2800) 
the degree of damage to the nerve fibers was quite striking, some fibers revealed complete delamination with fragmentation of myelin sheaths, and axons appeared quite distorted. At 1 to 2 weeks, there was further axonal degeneration, and myelin breakdown with a large population of macrophages actively digesting myelin. The process of wallerian degeneration was a constant finding distal to the site of injection suggesting that segmental demyelination was not the primary pathology. There was also at this time the earliest signs of regeneration with reduplicating Schwann cells and axonal sprouting (Fig. 7).

At 5 weeks an advanced stage of regeneration could be seen with a large population of small, thinly myelinated axons. At 2 months there was further regeneration with many larger, heavily myelinated fibers. Regeneration was a constant finding in nerves damaged by injection of the various agents with even the most severely injured nerves with total axonal degeneration undergoing subsequent regeneration. The rate of regeneration depended to some extent on the specific agent and dosage injected. The intrafascicular injection of an admixture of a compound and blood elements delayed but did not prevent regeneration.

\section{Alterations in Perineurial and Microvascular Permeability Following Nerve Injection Injury}

It is now established that under normal conditions peripheral nerve fibers function in a unique environment created and maintained by special barrier mechanisms (Olsson, 1966; Waksman, 1961; Olsson, 1971). Protein tracer techniques using Evans blue albumin and horeradish peroxidase have revealed that following intravenous injection in various animal species, these macromolecules remain confined to the lumen of the endoneurial microvessels and do not pass into the extravascular space of the endoneurium (Olsson and Reese, 1971) (Fig. 8, 9). When these tracer substances are applied to the surface of the nerves, they penetrate the epineurium and outer layers of the perineurium, but never beyond the

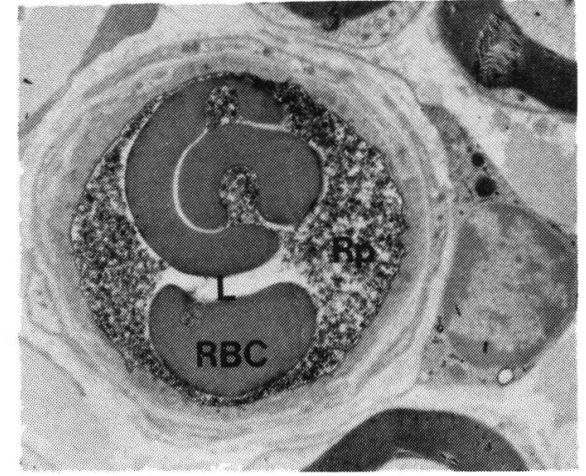

Figure 9-Electronmicrograph of normal rat sciatic nerve 2 hours after intravenous injection of horseradish peroxidase. The tracer protein evident as a dark reaction product is seen to fill the lumen of the endoneurial microvessel, with no evidence of leakage into the extravascular endoneurial space. $L$, lumen of endoneurial microvessel; $\mathrm{Rp}$, peroxidase reaction product; $R B C$, red blood cell. (Uranyl acetate stain omitted X 5580)

inner layers of the perineurium nor into the adjacent endoneurium (Fig. 10). This selective permeability of endoneurial microvessels and the inner layers of the perineurium to various macromolecules preventing their passage into the extravascular space immediately surrounding nerve fibers in the endoneurium is thought to constitute the blood-nerve barrier.

Alterations in the vascular permeability of peripheral nerves under various pathological conditions have been studied experimentally in various animal species. A marked increase in permeability of endoneurial microvessels and perineurium to locally applied or intravenously injected tracer proteins with extensive endoneurial edema have been reported following a crush lesion (Olsson, 1966) and ischemic injury (Lundborg, 1970) to peripheral nerve.

Our experimental studies using both fluorescent labelled albumin and horeradish peroxidase revealed a marked alteration in the distribution of these protein tracers following injection injury of rat sciatic nerve. Following intrafascicular injection, these tracer proteins were no longer confined to the epineurial sheaths and lumen of the endoneurial microvessels, but were seen throughout the endo- neurlal space between the nerve fibers (Fig. 11, 12, 13). Although most evident near the site of injection, leakage of protein was seen for up to 1 $\mathrm{cm}$. both proximally and distally.

The increased permeability of the perineurium and endoneurial vessels to these protein tracer substances suggested damage to blood-nerve barrier mechanisms. The resulting endoneurial edema with increased intrafascicular pressure and alteration in the normal endoneurial environment was felt to be a significant contributing factor to the neural damage seen with the intrafascicular type of injection. It is of interest that following extrafascicular drug injection, which was associated in the majority of cases with minimal or no nerve damage, there was no significant alteration in the distribution of the protein tracers from the normal nerve.

\section{TREATMENT OF NERVE INJECTION INJURIES:}

The management of injection injuries of peripheral nerves remains controversial. If the complication is noted immediately, some authors (Linden and Gurdjian, 1970) have advocated immediate operative exposure and irrigation of the nerve at the injection site. Matson (1950) recommended early exploration at three to four weeks with thorough external neurolysis. By contrast, others (Gilles and French, 1961) favour a conservative non-operative approach. In view of our own experimental studies and those of others, several points must be considered in formulating a strategy for the management of patients with nerve injection injuries. This includes information regarding the specific nerve involved, the nature of the injected compound and evidence for early return of function.

Our studies confirm that while certain druges are severely damaging when injected into peripheral nerve, others seem to have less potential for neural injury. This has led some authors (Clark, 1972) to suggest that if the substance injected is known to have significant neurotoxic properties, surgery is indicated and early. On the other hand, if the injected 


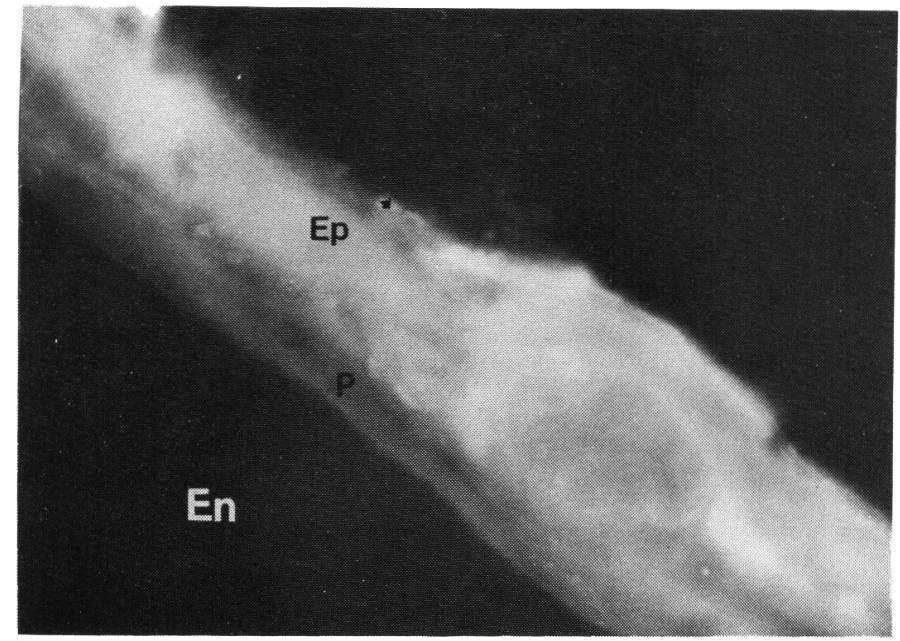

Figure $10-$ Fluorescent micrograph of normal rat sciatic nerve 1 hour following intravenous injection of Evans blue albumin. Fluorescence seen in the epineurial sheath extends toward the perineurium, but is prevented from entering the endoneurium by the inner layers of the perineurium. Ep, epineurium; P, perineurium, En, endoneurium. (X 2800)

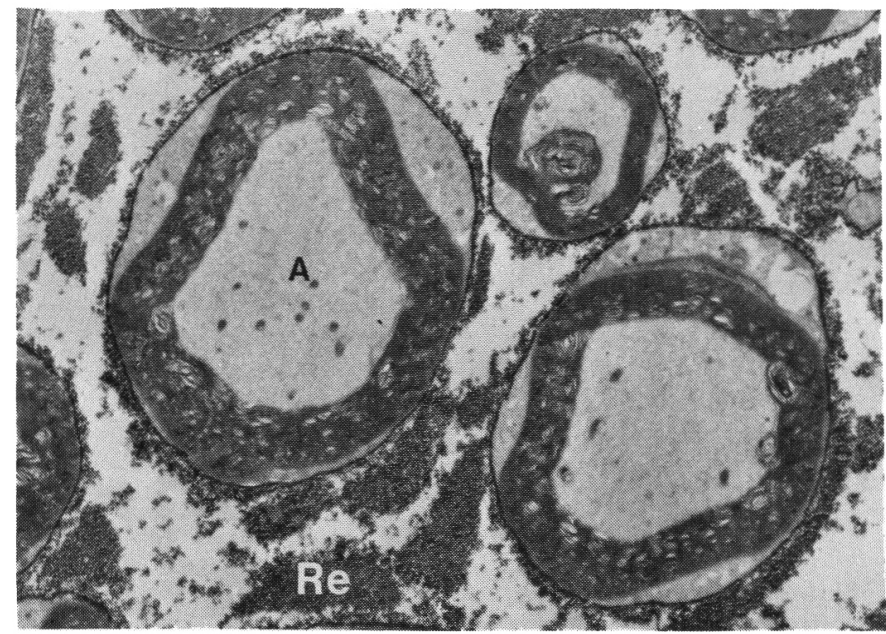

Figure 12 - Electronmicrograph of sciatic nerve 2 hours after intrafascicular injection of procaine $2 \%$ (Novocaine) with prior intravenous injection of horseradish peroxidase. Reaction product is evident throughout the endoneurium between the myelinated nerve fibers. $A$, axon; $R e$, reaction product in endoneurium. (Uranyl acetate stain omitted X 7750)

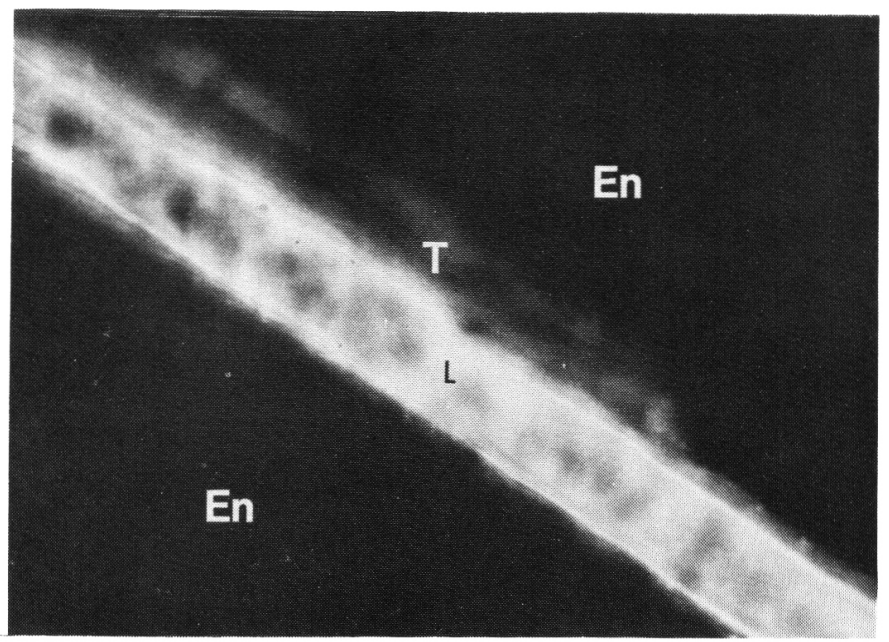

Figure 11 - Fluorescent micrograph of sciatic nerve 1 hour after intrafascicular injection of lidocaine $2 \%$ (Xylocaine) with prior intravenous injection of Evans blue albumin. Note that the fluorescence is no longer confined to the lumen of the endoneurial microvessel but has leaked into the adjacent endoneurial space. En, endoneurium; L, lumen of endoneurial microvessel; T, leakage of trace. (X 2800)

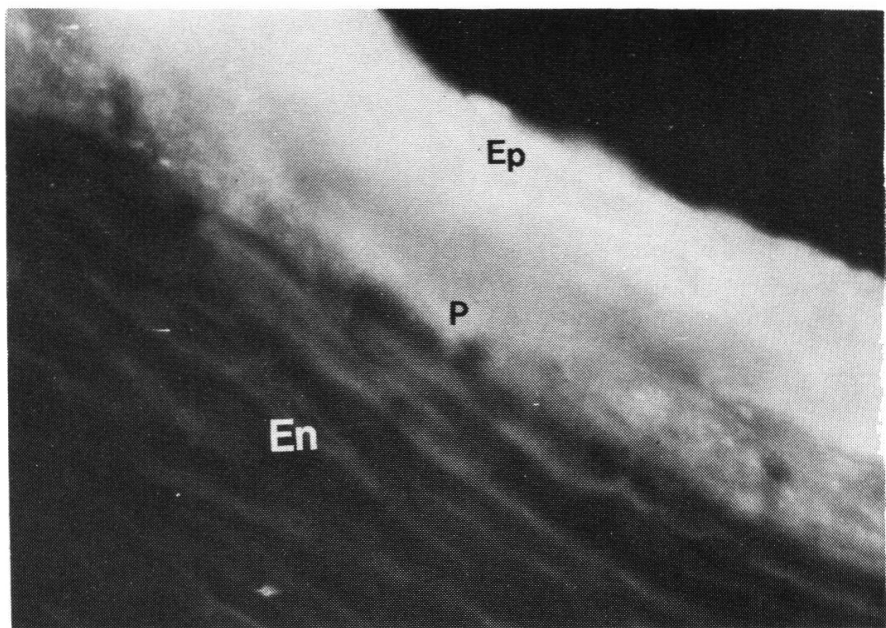

Figure 13 - Fluorescent micrograph of rat sciatic nerve 45 minutes after intrafascicular injection of tetracaine $1 \%$ (Pontocaine) with prior intravenous injection of EBA. The fluorescent tracer is seen to penetrate the perineurium and is evident throughout the interstices of the endoneurium. En, endoneurium; Ep, epineurium; P, perineurium. (X 2800) compound is known to have little neural tissue toxicity, a longer period of conservative management may be indicated. Likewise, injection injury of the sciatic nerve proximally in the thigh is less likely to end in complete spontaneous recovery than a distal lesion of the radial nerve in the forearm. Several authors have also stressed the importance of early return of function as a prognostic indicator of further subsequent recovery.

In view of the intraneural location of the pathological changes which begin quite soon following nerve injection (Gentili, 1979 B) any attempt at early operative intervention by external forms of neurolysis would appear to be of little value in reversing nerve fiber injury. Moreover, our observations that regeneration can occur following injection injuries in the experimental animal suggests that initially these patients be managed conservatively along the well-established lines for patients suffering from 
TABLE 2

Nerve Injury Following Injection of Local Anaesthetic Agents

\begin{tabular}{|c|c|c|c|c|}
\hline \multirow[t]{2}{*}{ AGENT } & \multirow[t]{2}{*}{ pH } & \multirow[t]{2}{*}{ OSMOLALITY } & \multicolumn{2}{|c|}{ DEGREE OF NERVE FIBER INJURY } \\
\hline & & & $\begin{array}{c}\text { Extrafascicular } \\
\text { Injection }\end{array}$ & $\begin{array}{l}\text { Intrafascicular } \\
\text { Injection }\end{array}$ \\
\hline $\begin{array}{l}\text { Lidocaine I \& } 2 \% \\
\text { (Astra) }\end{array}$ & 6.8 & $284-330$ & - & ++ \\
\hline $\begin{array}{l}\text { Lidocaine } 1 \& 2 \% \\
\text { + Epinephrine } \\
\text { (Astra) }\end{array}$ & $3.5-3.9$ & 298-301 & - & ++ \\
\hline $\begin{array}{l}\text { Lidocaine Hydrocarbonate } 2 \% \\
\text { (Astra) }\end{array}$ & 6.9 & 335 & - & +++ \\
\hline $\begin{array}{l}\text { Bupivacaine } .5 \% \\
\text { (Winthrop) }\end{array}$ & 5.5 & 281 & - & + \\
\hline $\begin{array}{l}\text { Mepivacaine } 1 \% \\
\text { (Winthrop) }\end{array}$ & 5.6 & 295 & - & + \\
\hline $\begin{array}{l}\text { Tetracaine } 1 \% \\
\text { (Winthrop) }\end{array}$ & $5.0-7.0$ & 455 & - & +++ \\
\hline $\begin{array}{l}\text { Procaine } 2 \% \\
\text { (Winthrop) }\end{array}$ & 3.5 & 286 & - & +++ \\
\hline
\end{tabular}

- $\quad$ no evidence of nerve damage

$+\quad$ minimal injury with occasional nerve fiber injury

+ moderate injury with focal axonal and myelin damage

+++ severe nerve fiber injury with widespread axonal and myelin degeneration

lesions in continuity (Kline and Hudson, 1976). However, one must be careful in extrapolating findings in experimental animals to man, and although similar to the human nerve in histological sturcture, rate sciatic nerve does not respond to any type of injury in exactly the same fashion as human nerve. Indeed, regeneration has not always been the case with reported human nerve injection injuries (Hudson et al, 1979). It is therefore essential that these injuries be followed closely and that conservative management not be prolonged in those patients who do not exhibit recovery in the appropriate period following injury.

The main indication for surgical intervention following nerve injection injury is a significant deficit in a nerve whose function is considered important for adequate limb function, and which has been present long enough that further delay would jeopardize any chance of reinnvervation of endorgans. The presence of severe persistent pain in the distribution of the injected nerve even in the face of adequate motor recovery may be another indication for surgical explor- ation. At operation, careful inspection of the nerve with the aid of the operating microscope is important. However, external appearance of the nerve may be misleading in view of the intraneural location of the pathology. Several authors (Kline et al, 1969; Hudson et al, 1979) have stressed the importance of intraoperative neurophysiological studies in assessing the presence and rate of regeneration and in deciding whether resection and suture is indicated. At operation care must be taken to appreciate the whole extent of the lesion which often effects a much longer segment of the nerve than might be expected. The role of external neurolysis remains unsettled (Clark et al, 1970). Clinical experience suggests that it may have a limited role in the treatment of nerve injection injuries in which spontaneous pain remains a significant problem.

\section{REFERENCES}

BONICA, J.J. (1954). The Management of Pain, 2nd Ed. Lea and Febiger, Philadelphia. 227-228.
BROADBENT, T.R., ODOM, G.L, WOODHALL, B. (1948). Peripheral Nerve Injuries from Administration of Penicillin, J.A.M.A. 140: 1008-1010.

BURKEL, W.E., McPHEE, M.A. (1970). Effect of Phenol injection into Peripheral Nerve of Rat, Arch. Phys. Med. \& Rehab. 51: 391-397.

CHINO, N., AWAD, E.A., KOTTKE, F.J.A. (1974). Pathology of Propylne Glycol Administered by Perineurial and Extramuscular Injection in Rats. Arch. Phys. Med. Rehab. 55: 33-38.

CLARK, K., WILLIAMS, P.E. Jr., WILLIS, W., McGRAVAN, W.A. (1970). Injection Injury of the Sciatic Nerve, Clin. Neurosurg. 17: $111-125$.

CLARK, W.K.A. (1972) Surgery for Injection Injuries of Peripheral Nerves. Surg. Clinic of North Amer. 52: 1325-1328.

COMBES, M.S., CLARK, W.K., GREGORY, C.F., JAMES, J.A. (1960). Sciatic Nerve Injury in Infants: Recognition and Prevention of Impairment Resulting from Intragluteal Injection, J.A.M.A. 173: 1330-1339.

COMBES, M.A. and CLARK, W.K.A. (1960). Sciatic Nerve Injury Following Intragluteal Injection: Pathogenesis and Prevention. Amer. J. Dis. Child: 100-579. (abstr.)

CURTIS, P.A. Jr., TUCKER, H.J.A. (1960). Sciatic Palsy in Premature Infants: A Report and Follow-up Study of 10 Cases, J.A.M.A. 174: 1586-1588.

GENTILI, F., HUDSON, A.R., KLINE, D., HUNTER, D. (1979A). Peripheral Nerve Injection Injury. An Experimental Study. Neurosurgery 4: 244-253. 
GENTILI, F., HUDSON, A.R., HUNTER, D. (1979B). Early Changes following Injection Injury of Peripheral Nerves - A Light E.M. and Fluorescent Microscopic Study. (accepted by Can. J. Surgery, issue of March 1980)

GENTILI, F., HUDSON, A.R., HUNTER, D., KLINE, D. (1979C). Nerve Injection Injury with Local Anaesthetic Agents - A Light, Electron Microscopic, Fluorescent Microscopic and Horseradish Peroxidase Study. (accepted by Neurosurgery, issue of March 1980)

GILLES, F.H., FRENCH, J.H. (1961). Postinjection Sciatic Nerve Palsies in Infants and Children, J. Pediat. 58: 195-204.

GRAHAM, R.C., KARNOVSKY, M.J. (1966). The Early Stages of Absorption of Injected Horseradish Peroxidase in the Proximal Tubules of the Mouse Kidney. Ultrastructural Correlates by a New Technique. J. Histochem. Cytochem. 14: 291-302.

HANSON, D.J.A. (1963). Intramuscular Injection Injuries and Complications, Gen. Pract. 27: 109-115.

HOLBROOK, T.J., PILCHER, C. (1950). The Effects of Injection of Penicillin. Peanut Oil and Beeswax, Separately and in Combination Upon Nerve and Muscle, Surg. Gyn. Obs. 90: 39-44.

HUDSON, A., KLINE, D.G., GENTILI, F. (1980). Management of Peripheral Nerve Problems. Ed. George E. Omer, M.D. and Morton Spinner, M.D., W.B. Saunders Co., Phil., p. 639-653.

KLINE, D.G., HUDSON, A. (1976). Early Management of Peripheral Nerve Injury. In Current Controversies in Neurosurgery, edited by T.P. Morley. Saunders 181-198.

KOLB, L.C., GRAY, S.J. (1946). Peripheral
Neuritis as a Complication of Penicillin Therapy, J.A.M.A. 132: 323-326.

LINDEN, D.W., GURDJIAN, E.S. (1970). Injuries of Nerves. Clinical Aspects in Handbook of Clinical Neurology, Vol. 7, Part 1, Chapter 8: 257-264, North-Holland Publishing Co., Amsterdam.

LING, C.M., LOONG, S.C. (1976). Injection of the Radial Nerve Injury 8: 60-62.

LUNDBORG, GORAN (1970). Ischemic Nerve Injury. Experimental Studies on Intraneural Microvascular Pathophysiology and Nerve Function in a Limb Subjected to Temporary Circulatory Arrest. Scandinavian J. Plast Reconstr. Surg. Supplement 6, 1970.

MATSON, D.D. (1950). Early Neurolysis in the Treatment of Injury of the Peripheral Nerves Due to Faulty Injection of Antibiotics, New Eng. J. Med. 242: 973-975.

MOORE, D.C. (1955). Complications of Regional Block, Charles C. Thomas, Springfield, Mass. 112-118.

OLSSON, Y.A. (1966). Studies on Vascular Permeability in Peripheral Nerves. 1. Distribution of Circulating Fluorescent Serum Albumin in Normal, Crushed and Sectioned Rat Sciatic Nerve, Acta. Neuropathologica 7: 1-15.

OLSSON, Y., REESE, T. (1971). Permeability of Vasa Nervorum and Perineurium in Mouse Sciatic Nerve Studied by Fluorescence and Electron Microscopy, J. Neuropath. Exp. Neurol. 30: 105.

SCHEINBERG, L., ALLENSWORTH, M. (1957). Sciatic Neuropathy in Infants Related to Antibiotic Injections, Pediatrics 19: 261265.

SELANDER, D., DHUNER, K.G., LUNDBORG, G. (1977). Peripheral Nerve Injury Experimental Study of the Acute Effects of Needle
Point Trauma, Acta Anaesth. Scand. 21: 182-188.

SELANDER, D., BRATTSAND, R., LUNDBORG, G., NORDBORG, C., OLSSON, Y. (1979). Local Anaesthetic: Importance of Mode of Application, Concentration and Adrenalin for the appearance of Nerve Lesions. Acta. Anesth. Scand. 23: 127-136.

STEINWALL, O., and KLATZO, I. (1966). Selective Vulnerability of the Blood-Brain Barrier in Chemically induced Lesions, J. Neuropath. Exp. Neurol. 25: 542-559.

SUN, C.N., WHITE, H.J. (1974). Dysfunction and Remyelination of Peripheral Nerve After Alcohol Injury, Exp. Path. 9: 169-174.

TARLOV, I.M., PERLMUTLER, I. (1951). Berman, A.N.: Paralysis Caused by Penicillin Injection: Mechanism of Complication - A Warning, J. Neuropath. Exp. Neurol. 10: 158-176.

TURNER, G.G. (1920). The Site for Intramuscular Injections, Lancet 2: 819.

VON HOCHSTETTER, A. (1955). Problems and Technique of Intragluteal Injections. I. Influence of Medication and Patient Characteristics on the Development of Syringe Injuries, Schweiz, Med. Wschr. 85: 11381144.

WAKSMAN, B.H. (1961). Experimental Stdy of Diptheric Polyneuritis in the Rabbit and Guinea Pig. IIl The Blood-Nerve Barrier in the Rabbit, J. Neuropath. Exp. Neurol. 20: 35-77.

WOODALL, B., BROADBENT, T.R., TAVER. J. (1950). The Neuropathology of Antibioticinduced peripheral nerve paralysis Surg. Forum 1: 394-399. 